\title{
Modelling the growth rate of Listeria monocytogenes in cooked ham stored at different temperatures
}

\author{
Jacek Szczawiński ${ }^{1}$, Małgorzata Ewa Szczawińska ${ }^{1}$, Adriana Łobacz ${ }^{2}$, \\ Michał Tracz ${ }^{1}$, Agnieszka Jackowska-Tracz ${ }^{1}$ \\ ${ }^{1}$ Department of Food Hygiene and Public Health, Faculty of Veterinary Medicine, \\ University of Life Sciences, 02-776 Warsaw, Poland \\ ${ }^{2}$ Chair of Dairy and Quality Management, Faculty of Food Sciences, \\ University of Warmia and Mazury in Olsztyn, 10-719 Olsztyn, Poland \\ jacek_szczawinski@sggw.pl \\ Received: August 23, 2016 Accepted: March 10, 2017
}

\begin{abstract}
Introduction: The purpose of the study was to determine and model the growth rates of L. monocytogenes in cooked cured ham stored at various temperatures. Material and Methods: Samples of cured ham were artificially contaminated with a mixture of three L. monocytogenes strains and stored at $3,6,9,12$, or $15^{\circ} \mathrm{C}$ for 16 days. The number of listeriae was determined after 0,1 , $2,3,5,7,9,12,14$, and 16 days. A series of decimal dilutions were prepared from each sample and plated onto ALOA agar, after which the plates were incubated at $37^{\circ} \mathrm{C}$ for $48 \mathrm{~h}$ under aerobic conditions. The bacterial counts were logarithmised and analysed statistically. Five repetitions of the experiment were performed. Results: Both storage temperature and time were found to significantly influence the growth rate of listeriae $(\mathrm{P}<0.01)$. The test bacteria growth curves were fitted to three primary models: the Gompertz, Baranyi, and logistic. The mean square error (MSE) and Akaike's information criterion (AIC) were calculated to evaluate the goodness of fit. It transpired that the logistic model fit the experimental data best. The natural logarithms of L. monocytogenes' mean growth rates from this model were fitted to two secondary models: the square root and polynomial. Conclusion: Modelling in both secondary types can predict the growth rates of L. monocytogenes in cooked cured ham stored at each studied temperature, but mathematical validation showed the polynomial model to be more accurate.
\end{abstract}

Keywords: ham, storage, Listeria monocytogenes, predictive modelling.

\section{Introduction}

Listeria monocytogenes causes listeriosis, a disease highly fatal $(30 \%-40 \%)$ to foetuses, newborns, infants, pregnant women, and elderly and immunocompromised individuals such as those with cancer, renal diseases, heart diseases, or AIDS. People receiving organ transplants and treated with immunosuppressive drugs are also susceptible to listeriosis $(3,27)$.

Over 10,000 cases of human infection were published in medical literature during 1960-1982. An estimated 23,150 cases (5463 fatal) of listeriosis occurred worldwide in 2010 (3). The incidence of listeriosis in the United States is approximately 0.7 per 100,000 people per year (3). In the European Union (EU), 1763 confirmed human cases of listeriosis were reported in 2013 by 27 member states (MS). The EU notification rate was 0.44 cases per 100,000 population, which indicated an $8.6 \%$ increase compared to 2012 .
There was a statistically significant increasing trend of listeriosis in the EU and European Economic Area (EEA) during 2009-2013. A total of 191 deaths due to listeriosis were reported in 2013. The highest number of fatal cases (64) was reported in France. The mortality rate in the EU was established at $15.6 \%$ among cases with known outcome. In 2013, a total of 13 outbreaks caused by L. monocytogenes were reported by seven MS and one non-MS. It was observed that the number of listeriosis cases was slightly higher in 2013 than in previous years (13).

An increasing trend in the number of cases of listeriosis in humans has been also observed in Poland (8). The calculated median of listeriosis cases in Poland between 2007 and 2011 was 43 with an average incidence rate of 0.11 per 100,000 population. In total, 58 cases of listeriosis with an incidence rate of 0.15 were reported in Poland in 2013 (30). 
L. monocytogenes has been isolated from many kinds of food, including ready-to-eat (RTE) meat products $(1,9,10,12)$. According to a European Food Safety Authority (EFSA) report, the non-compliance in 2013 for different categories of RTE food was generally at a comparable level to previous years (13). Nevertheless, a higher level of non-compliance was observed in case of fishery products at processing plant level (mainly smoked fish). Consistent with the results of the baseline study on the prevalence of $L$. monocytogenes in certain RTE foods in the EU between 2010 and 2011, the observed proportion of positive samples in retail products was the highest in fishery products, followed by soft and semi-soft cheeses, RTE meat products, and hard cheeses (12).

L. monocytogenes belongs to the psychrotrophic microorganisms able to multiply in food stored under refrigeration. Even a small number of listeriae present in some RTE products can grow to a level which threatens consumer health $(3,27,28)$. The growth of L. monocytogenes can be particularly dynamic in food stored under temperature abuse conditions, which often occurs both in food trade and domestic refrigerators $(19,20)$.

Therefore, accurate information on the behaviour of $L$. monocytogenes in meat products constitutes crucial knowledge for the Microbiological Risk Assessment (MRA) process, as well as the Hazard Analysis and Critical Control Point (HACCP) system. The experimental data regarding survival, inactivation, and growth of this foodborne pathogen during production and storage of meat products at different temperatures can be described mathematically by predictive models $(2,15,17,32)$. Predictive microbiology is based on the assumption that the reaction of microorganisms to environmental factors is reproducible. By experimental determination of parameters having the most important effects on microorganism behaviour, it is possible to predict the response of microbial pathogens to processes applied in food hygiene and technology $(4,11)$.

Predictive microbiology has become an important tool supporting food safety management systems in recent years. Moreover, predictive microbial models are commonly being used by food inspectors and food technologists in their everyday work $(2,17,33)$.

The aims of the present study were as follows: to determine the growth rates of $L$. monocytogenes in cooked cured ham stored at various temperatures; to describe the microbiological data by using primary and secondary mathematical models; and to generate equations enabling prediction of the behaviour of L. monocytogenes in cooked ham stored under different temperature conditions.

\section{Material and Methods}

Inoculum preparation. The three following reference strains of L. monocytogenes were used in the study: ATCC No. 7644 (isolated from human), ATCC
No. 15313 (isolated from rabbit), and ATCC No. 19112 (isolated from human spinal fluid). In order to prepare the inoculum, the organisms were cultured in $10 \mathrm{~mL}$ nutrient broth at $37^{\circ} \mathrm{C}$ for $24 \mathrm{~h}$. The L. monocytogenes cultures were mixed together in the stationary phase of growth and diluted to obtain a suspension containing approx. $10^{4} \mathrm{cfu} / \mathrm{cm}^{3}$. The inoculum density was determined by surface plating of bacterial suspension onto ALOA - Agar Listeria Ottaviani \& Agosti medium (Merck, Poland).

Material. Cooked ham was purchased from a local producer (meat processing plant, Kozienice, Poland). The production stages of the ham included wet-brine curing, light smoking, and cooking to internal temperature of $70^{\circ} \mathrm{C}$. The composition of the ham declared by the producer was as follows: pig hind leg (75\%), water, natural spices and their extracts, sodium chloride, E-250, E-316, E-407, E-452, and E-621. Polish standard PN-A-82007 lays down the chemical and microbiological requirements for this ham (26).

Inoculation and storage of ham. Samples of ham $(10 \mathrm{~g})$ were placed in polyethylene pouches and inoculated with $L$. monocytogenes by adding $0.1 \mathrm{~cm}^{3}$ bacterial suspension to each pouch. The samples were transferred to incubators directly after inoculation and stored at $3,6,9,12$ and $15^{\circ} \mathrm{C}$ for $384 \mathrm{~h}$.

Bacteriological examination. Enumeration of L. monocytogenes in ham samples was performed after $0,24,48,72,120,168,216,288,336$, and $384 \mathrm{~h}$ of storage. The samples were homogenised with dilution fluid for $2 \mathrm{~min}$, ten-fold dilution series were prepared, and from each dilution $0.5 \mathrm{~cm}^{3}$ was taken and plated onto ALOA medium. The plates with culture medium were incubated under aerobic conditions at $37^{\circ} \mathrm{C}$ for $48 \mathrm{~h}$. The colonies grown on plates were counted, bacterial counts were multiplied by the appropriate dilutions, and numbers of colony-forming units were calculated.

pH measurement. The $\mathrm{pH}$ of uncontaminated samples of ham stored at $3,6,9,12$, and $15^{\circ} \mathrm{C}$ was determined using a Schott Instruments digital $\mathrm{pH}$ meter equipped with a temperature sensor. During calibration of the equipment and measurements the effect of temperature on $\mathrm{pH}$ was taken into account.

Statistical calculations. Bacterial counts were transformed into decimal and natural logarithms. The calculations and modelling were conducted on transformed data using IBM SPSS Statistics 23, Statistica 10 (StatSoft, Polska) and Microsoft Office Excel 2007. The experiment was carried out in five replicates.

Primary modelling - curve fitting. The growth curves of L. monocytogenes were fitted to modified Gompertz, logistic, and Baranyi models. The bacterial growth in foods is most frequently described by the modified Gompertz (Eq. 1) and logistic models (Eq. 2) $(15,21,24)$ :

$$
\begin{aligned}
& x(t)=C+A \exp (-\exp (-B(t-M))) \\
& x(t)=C+\frac{A}{1+\exp (-B(t-M))}
\end{aligned}
$$


where $x(t)$ is $\log 10(\mathrm{CFU} / \mathrm{g})$ of cell concentration at time $t ; C$ is the value of the lower asymptote in units of $\log 10(\mathrm{cfu} / \mathrm{g}) ; A$ is equal to $\log 10(x \max / x 0) ; x 0$ is the initial population density; $x \max$ is the maximum population density; $B$ is the maximum relative growth rate at $M(1 / \mathrm{h})$; and $M$ is the time at which the absolute growth rate is maximum (hours). Baranyi and Roberts (2) introduced a mechanistic model that describes sigmoidal bacterial growth curves. It is referred to as the Baranyi model and described by the following equations:

$y(t)=y_{0}+\mu_{\max } F(t)-\ln \left(1+\frac{e^{\mu_{\max } F(t)}-1}{e^{\left(y_{\max }-y_{0}\right)}}\right)$

$F(t)=t+\frac{1}{v} \ln \left(e^{-v t}+e^{-h_{0}}-e^{\left(-v t-h_{0}\right)}\right)$

where $y(t)$ is the cell concentration at time $t(\ln \mathrm{CFU} / \mathrm{g})$, $y 0$ is the initial cell concentration ( $\mathrm{ln} \mathrm{CFU} / \mathrm{g}), y \max$ is the maximum cell concentration (ln $\mathrm{CFU} / \mathrm{g})$, mmax is the maximum specific growth rate $(1 / \mathrm{h}), v$ is the rate of increase in the limiting substrate, and $h O$ is a product of

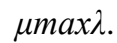

The modified Gompertz and logistic equations' parameters (A, B, C, M) were subsequently used to calculate: lag phase duration $(\mathrm{h})=\mathrm{M}-(1 / \mathrm{B})$, generation time $(\mathrm{h})=(\log 2 \mathrm{e}) / \mathrm{BC}(\log$ denotes the decimal basis of the logarithm), exponential growth rate $[(\log \mathrm{cfu} / \mathrm{g}) / \mathrm{h}]=$ $\mathrm{BC} / \mathrm{e}$, and maximum population density $(\log \mathrm{cfu} / \mathrm{g})=$ $\mathrm{A}+\mathrm{C}(15,21,24)$.

The goodness of fit was evaluated by calculating the mean square error (MSE) and Akaike's information criterion (AIC) for each of the studied primary models according to the following equations:

- the mean square error $(M S E)$ :

$M S E=\frac{R S E}{d f}$

where $R S E$ is the residual sum of errors and $d f$ is degrees of freedom.

- Akaike's Information Criterion with bias adjustment for small sample size (6).

$A I C_{c}=-2 * \ln ($ likelihood $)+2 * K+(2 * K *(K+$ 1))/(n-K-1)

where $n$ is number of observations and $K$ is the number of model parameters.

Secondary modelling. The natural logarithms of mean growth rates of $L$. monocytogenes were calculated from the primary logistic model and fitted to the secondary models, namely the square root (7) and polynomial (8) according to the following functions:

$\sqrt{\mu_{\max }}=a\left(T-T_{\text {min }}\right)$

$\mu_{\max }=a_{0}+a_{1} T+a_{2} T^{2}$

where $\mu_{\max }$ is growth rate $(1 / \mathrm{h}), a_{0}, a_{1}$, and $a_{2}$ are adjustment factors, $\mathrm{T}$ is temperature $\left({ }^{\circ} \mathrm{C}\right)$, and $\mathrm{T}_{\min }$ is the determined minimum temperature for the growth of microorganisms $\left({ }^{\circ} \mathrm{C}\right)$.

The internal mathematical validation of the secondary models was conducted by calculating accuracy $\left(A_{f}\right)$ and bias $\left(B_{f}\right)$ factors as suggested by Ross (29):

$$
\begin{aligned}
& A_{f}=10^{\left(\sum\left|\log \mu_{\text {predicted }} / \mu_{\text {observed }}\right| / n\right)} \\
& B_{f}=10^{\left(\sum \log \left(\frac{\mu_{\text {observed }}}{\mu_{\text {predicted }}}\right) / n\right)}
\end{aligned}
$$

where $n$ is the number of observations, $\mu_{\text {predicted }}$ is the predicted specific growth rate $(1 / \mathrm{h})$, and $\mu_{\text {observed }}$ is the observed specific growth rate $(1 / \mathrm{h})$.

The bias factor $B_{f}$ indicates consistent over- and under-prediction, whereas the coefficient of accuracy $A_{f}$ shows the mean difference between the logarithms of the observed and predicted values (10).

\section{Results}

The raw experimental data on changes in the number of listeriae in the samples of ham stored at 3,6, 9,12 , and $15^{\circ} \mathrm{C}$ and fitted to the primary logistic model are presented in Fig. 1.

The number of listeriae remained almost the same for the entire period of the experiment in the samples kept at $3^{\circ} \mathrm{C}$. In the samples stored at higher temperatures, growth of L. monocytogenes was observed (Fig. 1).

Analysis of variance showed that the effect of storage time on the number of listeriae in samples stored at $3{ }^{\circ} \mathrm{C}$ was not statistically significant $(\mathrm{P}<0.01)$, whereas in samples stored at $6,9,12$, and $15^{\circ} \mathrm{C}$ storage time exerted statistically significant influence $(\mathrm{P}<0.01)$ on the number of tested microorganisms (Fig. 1). The growth rate of $L$. monocytogenes increased simultaneously with incubation temperature, being the most dynamic at the highest applied temperature of $15^{\circ} \mathrm{C}$.

The results of calculations given in Table 1 allow detailed comparison of the performance of the applied primary models. The mean square error (MSE) as well as Akaike's information criterion (AIC) indicate that the logistic model showed the best fit to the experimental L. monocytogenes growth rate results in the ham samples stored at $6,9,12$, and $15^{\circ} \mathrm{C}$. Both the logistic and modified Gompertz models gave the same fit to data related to the samples stored at $3^{\circ} \mathrm{C}$ in terms of MSE and AIC values. It should be emphasised that the differences in the goodness of fit between the logistic and modified Gompertz models were very low. In all groups of samples the Baranyi model provided the worst fit (Table 1).

The growth kinetics presented in Table 2 were calculated from logistic equations. The values demonstrated that together with increasing storage temperature, decreases in lag time and generation time as well as an increase in the exponential growth rate of the tested microorganisms regularly occurred.

Because comparison of three primary models showed that the logistic model yielded the best goodness of fit, the mean growth rates of L. monocytogenes calculated from logistic equations were fitted to two secondary models. The results related to the square root and polynomial models are presented in Figs 2 and 3, respectively.

The results shown in Figs 2 and 3 demonstrate that both secondary models, namely the square root and polynomial, can be efficiently used to predict the growth rate of listeriae in ham during storage at temperatures in the range $3-15^{\circ} \mathrm{C}$. The accuracy $\left(A_{f}\right)$ and bias $\left(B_{f}\right)$ factors 
$3^{\circ} \mathrm{C}$

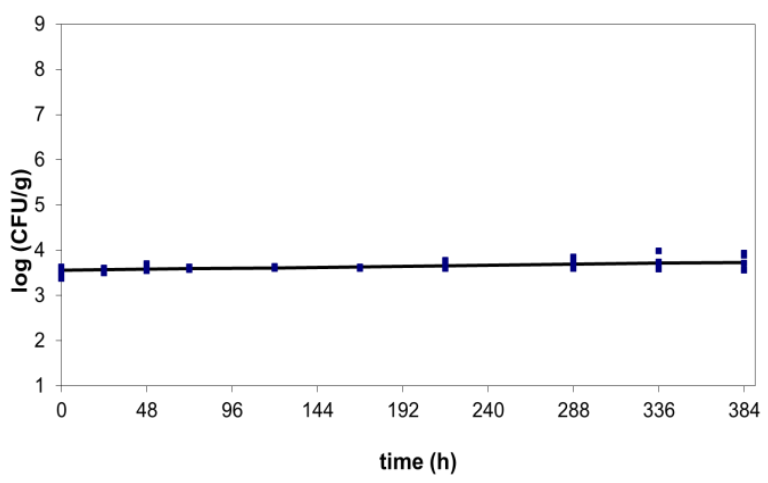

$9^{\circ} \mathrm{C}$

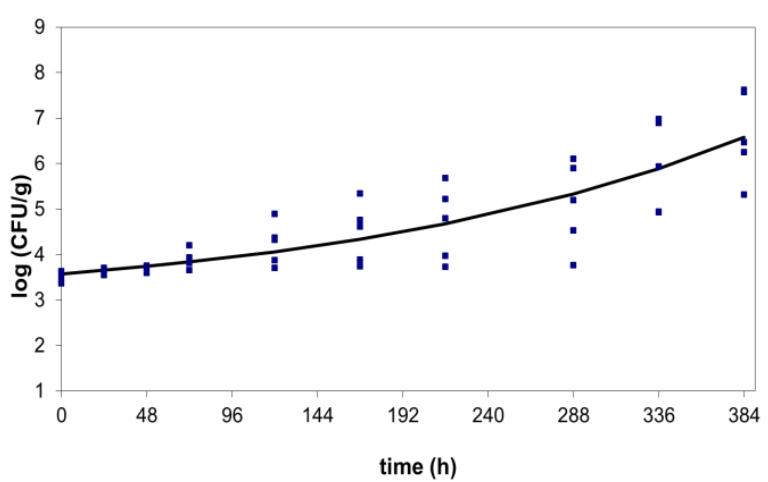

$6^{\circ} \mathrm{C}$

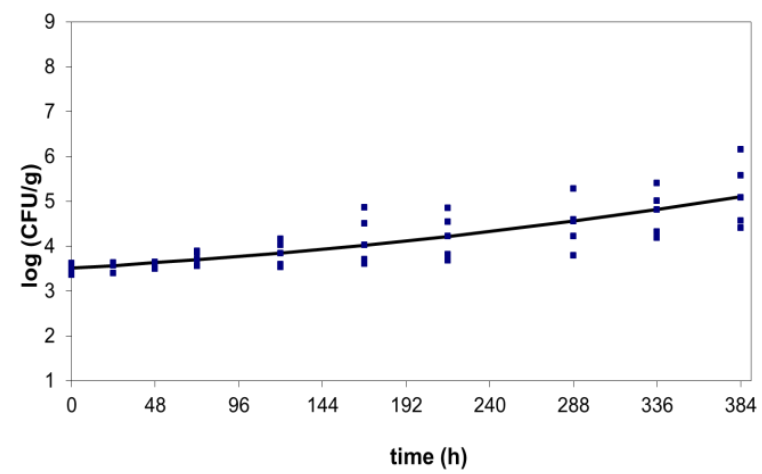

$12^{\circ} \mathrm{C}$

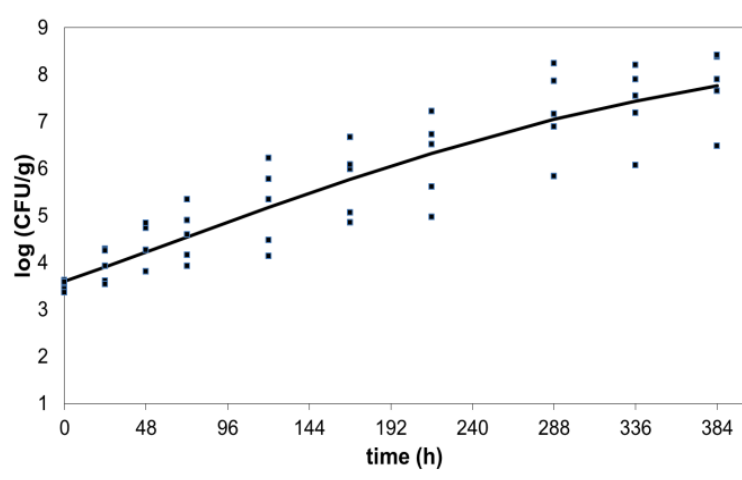

$15^{\circ} \mathrm{C}$

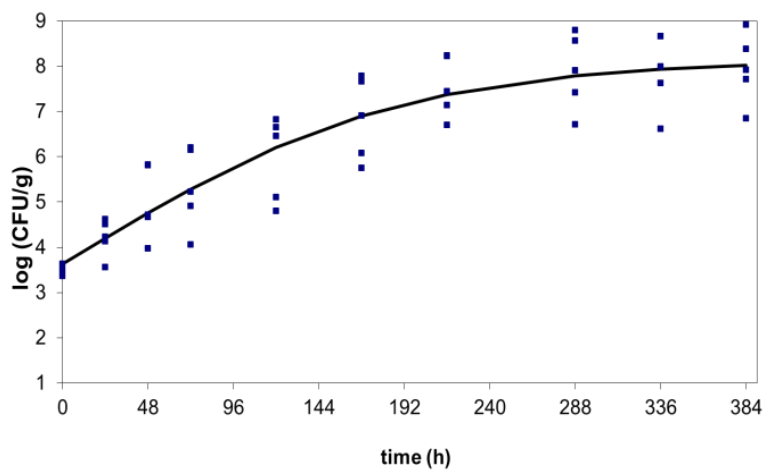

Fig. 1. Growth of Listeria monocytogenes in cooked ham stored at 3, 6, 9, 12, and $15^{\circ} \mathrm{C}$. Raw data from five replicates of the experiment are represented by black squares. Predicted values calculated from the logistic model are represented by the solid line

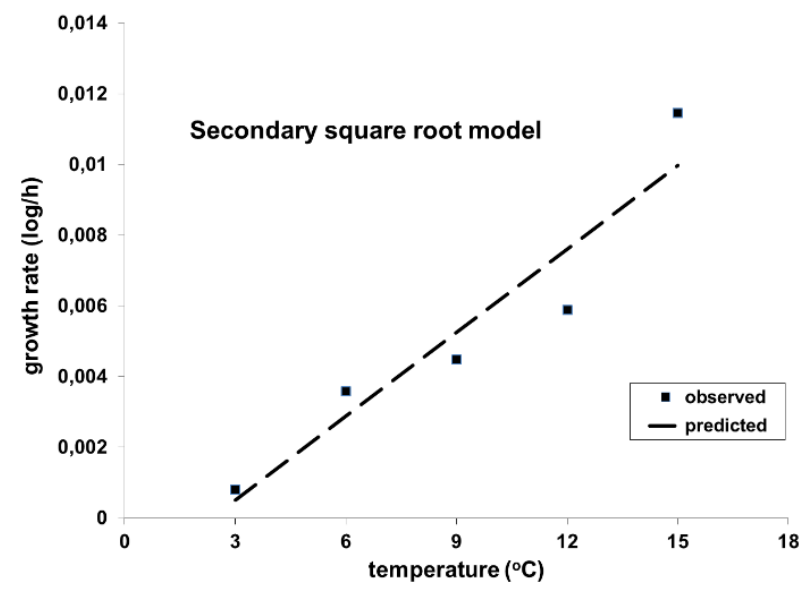

Fig. 2. The relationship between storage temperature and growth rate of Listeria monocytogenes in cooked ham. Observed mean values from five replicates fitted into secondary square root model

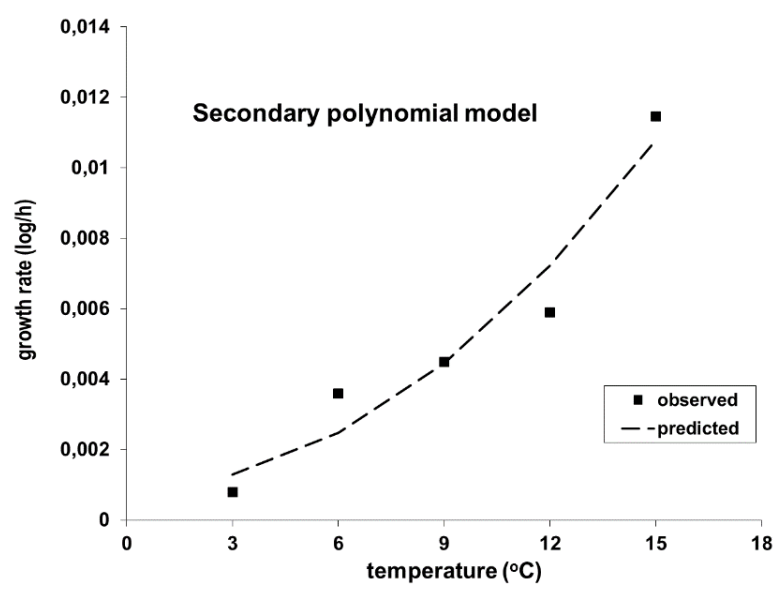

Fig. 3. The relationship between storage temperature and growth rate of Listeria monocytogenes in cooked ham. Observed mean values from five replicates fitted into secondary polynomial model 
Table 1. Statistics obtained from three compared primary models. The goodness of fit was estimated on the basis of the mean square error (MSE) and Akaike's information criterion (AIC)

\begin{tabular}{lllr}
\hline Storage temperature & Model & MSE & AIC \\
\hline $3{ }^{\circ} \mathrm{C}$ & Modified Gompertz & $0.0077^{*}$ & $-304.64^{*}$ \\
& Logistic model & $0.0077^{*}$ & $-304.64^{*}$ \\
& Baranyi model & 0.0178 & -260.74 \\
\hline $6^{\circ} \mathrm{C}$ & Modified Gompertz & 0.141 & -159.26 \\
& Logistic model & $0.1404^{*}$ & $-159.48^{*}$ \\
\hline & Baranyi model & 0.3237 & -115.71 \\
\hline${ }^{\circ} \mathrm{C}$ & Modified Gompertz & 0.3697 & -111.07 \\
& Logistic model & $0.3542^{*}$ & $-113.21^{*}$ \\
\hline $12^{\circ} \mathrm{C}$ & Baranyi model & 0.9679 & -62.95 \\
\hline & Modified Gompertz & 0.4128 & -105.55 \\
\hline & Logistic model & $0.4065^{*}$ & $-106.32^{*}$ \\
& Baranyi model & 0.9761 & -62.52 \\
\hline
\end{tabular}

* The model best fitting (the lowest value of MSE and AIC)

Table 2. Growth kinetics values calculated from the logistic equations

\begin{tabular}{|c|c|c|}
\hline Storage temperature & Growth kinetics & Logistic model \\
\hline \multirow{4}{*}{$3^{\circ} \mathrm{C}$} & Lag time (h) & 384 \\
\hline & Generation time (h) & 288.67 \\
\hline & Exponential growth rate $(\log / \mathrm{mL} / \mathrm{h})$ & 0.0008 \\
\hline & Max. pop. density (log/mL) & 3.725 \\
\hline \multirow{4}{*}{$6^{\circ} \mathrm{C}$} & Lag time $(\mathrm{h})$ & 150 \\
\hline & Generation time $(\mathrm{h})$ & 71.01 \\
\hline & Exponential growth rate $(\log / \mathrm{mL} / \mathrm{h})$ & 0.0036 \\
\hline & Max. pop. density $(\log / \mathrm{mL})$ & 5.16 \\
\hline \multirow{4}{*}{$9^{\circ} \mathrm{C}$} & Lag time $(\mathrm{h})$ & 100 \\
\hline & Generation time $(\mathrm{h})$ & 37.3 \\
\hline & Exponential growth rate $(\log / \mathrm{mL} / \mathrm{h})$ & 0.0047 \\
\hline & Max. pop. density $(\log / \mathrm{mL})$ & 6.64 \\
\hline \multirow{4}{*}{$12^{\circ} \mathrm{C}$} & Lag time $(\mathrm{h})$ & 50 \\
\hline & Generation time $(\mathrm{h})$ & 27.4 \\
\hline & Exponential growth rate $(\log / \mathrm{mL} / \mathrm{h})$ & 0.006 \\
\hline & Max. pop. density $(\log / \mathrm{mL})$ & 7.767 \\
\hline \multirow{4}{*}{$15^{\circ} \mathrm{C}$} & Lag time $(\mathrm{h})$ & 20 \\
\hline & Generation time $(\mathrm{h})$ & 26.27 \\
\hline & Exponential growth rate $(\log / \mathrm{mL} / \mathrm{h})$ & 0.0115 \\
\hline & Max. pop. density $(\log / \mathrm{mL})$ & 7.951 \\
\hline
\end{tabular}

Table 3. Comparison of accuracy $\left(A_{f}\right)$ and bias $\left(B_{f}\right)$ factors calculated for validation of the square root and polynomial secondary models describing the growth rate of $L$. monocytogenes in the samples of ham

\begin{tabular}{llcc}
\hline Secondary models & Equations & $A f$ & $B f$ \\
\hline Square root & $\sqrt{\text { growth rate }(\log )}=0.000787 * T-2.345932$ & 1.392 & 1.116 \\
\hline Polynomial & growth rate $(\log )=0.000893-0.00$ temp +0.0000439 temp $^{2}$ & $1.332^{*}$ & $1.086^{*}$ \\
\hline
\end{tabular}

* The model better fitted ( $A f$ and $B f$ values closer to 1.0)

(29) presented in Table 3 used for mathematical validation purposes suggest that in comparison to the square root model, the polynomial secondary model gave a better fit to the observed microbial data characterising the growth of $L$. monocytogenes in cooked ham (Table 3).
The obtained results demonstrated that contamination of cooked ham with L. monocytogenes after heat treatment poses a significant risk to consumer health, particularly high in cases of storage under temperature abuse conditions. 


\section{Discussion}

Among the food safety microbiological criteria which are given in EU Regulation 2073/2005 (14), particularly important for the manufacturers of meat products and food inspectors are those concerning L. monocytogenes in ready-to-eat (RTE) foodstuffs. Certain food categories are no longer under a zero tolerance regime but have a specified maximum allowed concentration of $100 \mathrm{CFU} / \mathrm{g}$ or $\mathrm{ml}$ for products placed on the market during their shelf-life. Therefore, many studies on modelling the effects of various factors on the growth of L. monocytogenes have been published in recent years $(5,18,22,23,35)$. This research allows the behaviour of $L$. monocytogenes in RTE meat products to be predicted.

In our previously conducted experiments, yogurt and other fermented dairy products were contaminated with L. monocytogenes and stored at temperatures of 3, $6,9,12$, and $15^{\circ} \mathrm{C}$. A linear decrease in the number of these bacteria was observed during storage $(34,35)$. This phenomenon was mainly explained by the low $\mathrm{pH}$ of the samples (range 4.1-4.4), because the $\mathrm{pH}$ value of about 4.6 is generally considered as the minimum enabling the growth of L. monocytogenes $(7,28)$. The initial average $\mathrm{pH}$ value of ham samples used in present study was 6.43 and increased to the range of $6.75-7.99$ at the end of storage.

A direct comparison of our results with other published studies is difficult because of differences in the experimental conditions. Comparison of the primary models applied in our study (Table 1) indicated that the logistic model best fitted the experimental results describing the growth of $L$. monocytogenes in the cooked ham samples. In a similar study, Luo et al. (22) modelled the growth kinetics of L. monocytogenes in RTE ham and sausage at temperatures from 4 to $35^{\circ} \mathrm{C}$. The observed data fitted four primary models well (the Baranyi, modified Gompertz, logistic, and Huang). The square root and the natural logarithm models were used to describe the relationship between temperature and lag time as well as the specific growth rate derived from the primary models. Mataragas et al. (23) determined the growth limits of L. monocytogenes in a vacuumpackaged sliced cooked cured meat product. The authors found that the Baranyi model appeared to fit the overall experimental data better than the modified logistic or modified Gompertz models.

The growth kinetics values calculated in the present study (Table 2) for L. monocytogenes in ham were compared to predicted values generated by the Pathogen Modeling Program (PMP) and ComBase Predictor (6). Lag times and generation times obtained from the PMP for L. monocytogenes incubated at $6,9,12$ and $15^{\circ} \mathrm{C}$ in optimum laboratory culture medium were much shorter than those observed in our studies (Table 2). Generation times obtained from ComBase were very similar to those obtained from the PMP. Predicted values for exponential growth rates given by ComBase were conspicuously higher than observed data at each of the applied storage temperatures in our experiment. All conducted comparisons demonstrated that the growth of L. monocytogenes in real meat product is much slower than in a laboratory culture medium assuming similar temperature, $\mathrm{pH}$, water activity, and concentration of $\mathrm{NaCl}$ and $\mathrm{NaNO}_{2}$.

It should be recognised that the results presented in this paper are specific to a particular product and also to the L. monocytogenes strains used in this study. Different growth rates might be obtained by testing in other environments and with L. monocytogenes from other sources (31). However, the cured, cooked ham used in this study met the requirements laid down in the Polish standard (26) and its manufacturing and chemical composition was typical for this kind of product. To obtain a more representative microorganism response, a mixture of three different strains of $L$. monocytogenes was used for sample inoculation. Therefore, we believe that the results obtained in the present study can be useful not only for the meat processing plant in Kozienice which produced the ham used in our experiments, but also for other Polish producers of cured, cooked ham.

The results demonstrated that the storage of food of animal origin at low temperatures is one of the most important factors limiting the number of food-borne illness outbreaks caused by bacterial pathogens, including L. monocytogenes, and even a minor breach of the provisions on required storage temperature and time can significantly increase the risk to consumer health.

Conflict of Interests Statement: The authors declare that there is no conflict of interests regarding the publication of this article.

Financial Disclosure Statement: The research was supported by a grant from the National Centre for Research and Development (NCBiR) and by a grant from the Foundation for Polish Science, PARENT/BRIDGE Programme - support for pregnant women conducting research, European funds within the Innovative Economy Operational Programme 20072013 (Measure 1.2 "Strengthening the human resources potential of science").

Animal Rights Statement: None required.

\section{References}

1. Ahmed O., Pangloli P., Hwang C., Zivanovic S., Wu T., D'Souza D. Draughon F.A.: The occurrence of Listeria monocytogens in retail ready-to-eat meat and poultry products related to the levels of acetate and lactate in the products. Food Control 2014 http://dx.doi.org/10.1016/j.foodcont.2014.12.015.

2. Baranyi J., Roberts T.A.: A dynamic approach to predicting bacterial growth in food. Int J Food Microbiol 1994, 23, 277-294.

3. Berger S.: Listeriosis: Global Status. GIDEON Informatics, Inc, Los Angeles, 2016. 
4. Black D.G., Davidson P.M.: Use of modeling to enhance the microbiological safety of the food system. Compr Rev Food Sci Food Saf 2008, 7, 159-167.

5. Buchanan R.L., Phillips J.G.: Response surface model for predicting the effects of temperature, $\mathrm{pH}$, sodium chloride content, sodium nitrite concentration, and atmosphere on the growth of Listeria monocytogenes. J. Food Protection 1990, 53, 370-376. http://wyndmoor.errc.ars.usda.gov/pubs/viewpub.aspx?iden=5478

6. ComBase 2016. http://browser.combase.cc/ComBase_Predictor. aspx?model=1\#

7. Corlett D.A., Brown M.H. pH and acidity. In: Microbial ecology of foods. Factors affecting life and death of microorganisms. International Commission on Microbiological Specification for Foods. Academic Press, New York, 1980, p 101.

8. Czarkowski M.P., Cielebąk E., Kondej B., Staszewska E.: Infectious diseases and poisonings in Poland in 2012. National Institute of Public Health - National Institute of Hygiene, Department of Epidemiology, Warsaw, 2013 pp. 24, 126.

9. Gómez D., Iguácel L.P., Rota M.C., Carramiñana J.J., Ariño A., Yangüela J.: Occurrence of Listeria monocytogenes in ready-toeat meat products and meat processing plants in Spain. Foods 2015, 4, 271-282.

10. Dalgaard P., Jorgensen L.V.: Predicted and observed growth of Listeria monocytogenes in seafood challenge tests and in naturally contaminated cold-smoked salmon. Int J Food Microbiol 1998, 40, 105-115.

11. Devlieghere F., Francois K., De Meulenaer B., Baert K.: Modelling Food Safety. In: Luning P.A, Devlieghere F., Verhe F. (ed) Safety in the agri-food chain. Wageningen Academic Publishers, the Netherlands 2006, pp. 397-417.

12. EFSA. European Food Safety Authority: Analysis of the baseline survey on the prevalence of Listeria monocytogenes in certain ready-to-eat (RTE) foods in the EU, 2010-2011 Part A: Listeria monocytogenes prevalence estimates. EFSA J 2013, 11, 3241.

13. EFSA. European Food Safety Authority: The European Union Summary Report on Trends and Sources of Zoonoses, Zoonotic Agents and Food-borne Outbreaks in 2013. EFSA J 2015, 13, 3991.

14. European Commission. 2005. Commission Regulation (EC) no. 2073/2005 of 15 November 2005 on microbiological criteria for foodstuffs. Official J Eur Union L 22.12.2005, 338, 1-26.

15. Gibson A.M., Bratchell N., Roberts T.A.: Predicting microbial growth: growth responses of salmonellae in a laboratory medium as affected by $\mathrm{pH}$, sodium chloride and storage temperature. Int $\mathbf{J}$ Food Microbiol 1988, 6, 155-178.

16. Giffel M.C., Zwietering M.H.: Validation of predictive models describing the growth of Listeria monocytogenes. Int. J. Food Microbiol., 1999, 46, 135-149.

17. Hoang H.M., Flick D., Derens E., Alvarez G., Laguerre O.: Combined deterministic and stochastic approaches for modeling the evolution of food products along the cold chain. Part II: A case study. Int J Refrig 2012, 35, 915-926.

18. Hwang C.A., Tamplin M.L.: Modeling the lag phase and growth rate of Listeria monocytogenes in ground ham containing sodium lactate and sodium diacetate at various storage temperatures. J Food Sci 2007, 72, M246-M253.
19. Laguerre O., Derens E., Palagos B.: Study of domestic refrigerator temperature and analysis of factors affecting temperature: a French survey. Int J Refrig 2002, 25, 653-659.

20. Likar K., Jevsnik M.: Cold chain maintaining in food trade. Food Control 2006, 17, 108-113.

21. López S., Prieto M., Dijkstra J., Ghanoa M.S., France J.: Statistical evaluation of mathematical models for microbial growth. Int J Food Microbiol 2004, 96, 289-300.

22. Luo K., Hong S.S., Oh D.H.: Modeling the effect of storage temperatures on the growth of Listeria monocytogenes on readyto-eat ham and sausage. J Food Prot 2015, 78, 1675-1681.

23. Mataragas M., Drosinos E.H., Siana P., Skandamis P., Metaxopoulos I.: Determination of the growth limits and kinetic behavior of Listeria monocytogenes in a sliced cooked cured meat product: validation of the predictive growth model under constant and dynamic temperature storage conditions. J Food Prot 2006, 69, 1312-1321.

24. McKellar R.C., Lu X.: Primary models. In: Modeling microbial responses in food, edited by R.C. McKellar, X. Lu, CRC Press LLC, Boca Raton, 2004, pp. 21-62.

25. Pathogen Modeling Program (PMP) Online. http://pmp.errc.ars.usda.gov/PMPOnline.aspx. Modified: 11/3/2015

26. Polish Standard: PN-A-82007 Meat products.

27. Posfay-Barbe K.M., Wald E.R.: Listeriosis. Semin Fetal Neonatal Med 2009, 14, 228-233.

28. Ray B., Bhunia A.: Control by low $\mathrm{pH}$ and organic acids. In: Fundamental food microbiology. CRC Press by Taylor \& Francis Group, Boca Raton, London, New York, 2008, p. 394

29. Ross T.: Indices for performance evaluation of predictive models in food microbiology. J Appl Bacteriol 1996, 81, 501-508.

30. Sadkowska-Todys M., Zieliński A., Czarkowski M.P.: Infectious diseases in Poland in 2013. Epidemiological Review 2015, 69, 195-204.

31. Seman D.L., Borger A.C., Meyer J.D., Hall P.A., Milkowski A.L.: Modeling the growth of Listeria monocytogenes in cured readyto-eat processed meat products by manipulation of sodium chloride, sodium diacetate, potassium lactate, and product moisture content. J Food Prot 2002, 65, 651-658.

32. Szczawińska M.E., Szczawiński J., Łobacz A.: Effect of temperature on the growth kinetics of Salmonella Enteritidis in cooked ham. Bull Vet Inst Pulawy 2014, 58, 47-56.

33. Szczawiński J. Predictive microbiology - practical applications. Med Weter 2012, 68, 540-543.

34. Szczawiński J., Stańczak B., Pęconek J.: Behaviour of Listeria monocytogenes in fermented milk products - prediction on the basis of experiments with real food products and Pathogen Modeling Program V. 4.0. In: Shelf life prediction for improved safety and quality of foods. Copernicus Project CIPA-CT94-0120. Copi-Print Library Building University College Dublin 1998, pp. 187-192.

35. Szczawiński J., Szczawińska M.E., Łobacz A., Jackowska-Tracz A.: Modeling the effect of temperature on survival rate of Listeria monocytogenes in yogurt. Pol J Vet Sci 2016, 19, 317-324. 